\title{
Improved postoperative lung function after sublobar resection of non-small-cell lung cancer combined with lung volume reduction surgery in patients with advanced emphysema
}

\author{
Claudio Caviezel, Julia von Rotz, Didier Schneiter, Ilhan Inci, Sven Hillinger, Isabelle Opitz, Walter Weder \\ Department of Thoracic Surgery, University Hospital Zurich, Switzerland \\ Contributions: (I) Conception and design: C Caviezel, J von Rotz, W Weder; (II) Administrative support: C Caviezel, J von Rotz, W Weder; (III) \\ Provision of study materials or patients: C Caviezel, J von Rotz, W Weder; (IV) Collection and assembly of data: C Caviezel, J von Rotz; (V) Data \\ analysis and interpretation: C Caviezel, J von Rotz, W Weder; (VI) Manuscript writing: All authors. (VII) Final approval of manuscript: All authors. \\ Correspondence to: Claudio Caviezel, MD. Department of Thoracic Surgery, University Hospital Zurich, Raemistrasse 100, Zürich 8091, Switzerland. \\ Email: claudio.caviezel@usz.ch.
}

\begin{abstract}
Background: Radiotherapy is recommended as primary local therapy for inoperable patients with non-small cell lung cancer (NSCLC). We hypothesized that selected patients with advanced emphysema could be candidates for surgery and improved functional outcome might result in addition to low mortality and morbidity and successful cancer control when sublobar resection in a lung volume reduction surgery (LVRS) concept is applied.

Methods: All patients with NSCLC and severe emphysema who underwent cancer resection in a LVRS concept between 2003 and 2015 were included for analysis. Postoperative 90-day mortality, complications, survival and lung function with forced expiratory volume in one second pre-operatively and three months postoperatively served as endpoints.

Results: Fourteen patients were included. Three procedures were bilateral and eleven unilateral, eight have been performed with thoracoscopy and six with conversion to an open procedure due to adhesions. In ten patients, tumor resection was atypical and in four patients an anatomic segmentectomy was performed. All patients had lung volume reduction. Prolonged air leak occurred in three patients. Perioperative 90-mortality was zero. Median pre-operative forced expiratory volume in one second was $32.5 \%$ and increased to $37 \%$ $(\mathrm{P}=0.002) 3$ months following surgery. Three and 5-year survival rates were $50 \%$ and $35 \%$, respectively.

Conclusions: Sublobar resection of NSCLC combined with LVRS in patients with severely impaired lung function due to emphysema can be performed with low mortality and morbidity making it an alternative treatment modality to radiotherapy. This approach allows cancer resection in marginal patients and improves emphysema symptoms simultaneously.
\end{abstract}

Keywords: Lung volume reduction surgery (LVRS); emphysema; cancer resection; sublobar resection

Submitted Mar 20, 2018. Accepted for publication Jun 12, 2018.

doi: $10.21037 /$ jtd.2018.06.79

View this article at: http://dx.doi.org/10.21037/jtd.2018.06.79

\section{Introduction}

Anatomical resection, primarily lobectomy or segmentectomy is so far the best choice for treatment of stage I non-small-cell lung cancer (NSCLC) (1). It leads to 5 -year survival rates of $73 \%$ up to $94 \%$ for pathologic stage IA patients $(2,3)$. According to several guidelines patients with impaired lung function are often precluded from this kind of pulmonary cancer resection (4-6). Operative mortality rates as high as $50 \%$ after lobectomy are reported in patients with NSCLC and severe emphysema $(6,7)$. For these so-called medically inoperable patients, other treatment modalities are offered. Stereotactic ablative radiotherapy (SBRT) and radiofrequency ablation (RFA) have been proven to be effective in NSCLC in this subgroup 
Table 1 Selection criteria for LVRS

\begin{tabular}{lll}
\hline Variable & Inclusion & Exclusion \\
\hline Patient & $\begin{array}{l}\text { Nicotine abstention }>4 \text { months; } \\
\text { passed pulmonary rehabilitation }\end{array}$ & Daily steroid intake $>20 \mathrm{mg}$ \\
CT morphology & Lung emphysema & Significant bronchiectasis \\
lung function & FEV1 $<45 \%$, TLC $>100 \%, \mathrm{RV}>150 \%$ & $\mathrm{FEV} 1<20 \%$ and diffusion capacity $<20 \%$ in homogeneous emphysema \\
6-MWD & $<450 \mathrm{~m}$ & - \\
Gas exchange & - & $\mathrm{paCO}_{2}>6.7 \mathrm{~Pa}, \mathrm{paO}_{2}<6.0 \mathrm{~Pa}$ in homogeneous emphysema \\
\hline
\end{tabular}

6-MWD, 6 minutes walking distance; CT, computed tomography; FEV1, forced expiratory volume in 1 second; RV, residual volume; RV/ TLC, RV-TLC-ratio (= hyperinflation); TLC, total lung capacity.

of patients $(8,9)$. Three-year survival of $55.8 \%$ is reported. Patients with severe pulmonary emphysema are a particular subgroup of these inoperable patients. They represent a management problem to both the surgeon and the radiation oncologist, especially when surgeons are not experienced in LVRS. Anatomical resection focused on tumor resection only is often precluded due to the impaired lung function and even limited surgery itself is questioned. It can be considered only when the concepts of volume reduction are applied. Pneumothorax is a rare complication following radiation therapy but more frequent and carrying more morbidity in severe emphysema $(10,11)$. Sublobar resection in form of wedge resections has not been clearly demonstrated to offer a better long-term oncological outcome in comparison to radiation therapy $(12,13)$. Patients with severe emphysema and distinct functional criteria and emphysema distribution on computer tomography (CT) scan might benefit from sublobar cancer resection in a lung volume reduction surgery (LVRS) concept. In addition to resection of the tumor there is a high probability of improving lung function as health-related quality of life and physical exercise capacity in selected patients (14-18). All morphologies of emphysema are possibly approachable for LVRS $(19,20)$. The aim of this retrospective study was to evaluate the functional and long term oncological outcome and morbidity and mortality of concomitant sublobar lung cancer resection and LVRS in selected patients.

\section{Methods}

\section{Database search}

The institution's LVRS database was searched for patients who have undergone tumor resection in LVRS concept between 2003 and 2015.

\section{Patient selection}

Patients were mostly evaluated for LVRS and suspicious lung nodules or proven lung cancer were found. They were referred originally from external pulmonologists and discussed at our institutional tumor board with the question for appropriate diagnostic steps or treatment considering their impaired lung function. Inclusion criteria for LVRS were adapted from our modified patient selection criteria (21) (Table 1). Emphysema morphology was defined as following (22): markedly heterogeneous is defined as a distinct regional difference in the severity of emphysema in at least two adjacent lung segments of either lung. Intermediately heterogeneous is a distinct regional difference in severity of emphysema with a maximum in the area of one or more than one but not in adjacent lung segments of either lung. Homogeneous emphysema shows no regional or only minor differences in the severity of emphysema.

Patients with homogeneous emphysema morphology were not included for surgery in this series.

The resection was primarily indicated when the tumor was in a LVRS target zone, on the same side as the LVRS target zone or when it was considered resectable by ipsilateral segmentectomy or wedge combined with contralateral LVRS during the same operation.

\section{Surgery}

LVRS was performed unilaterally or bilaterally by videoassisted thoracoscopic surgery (VATS) or by thoracotomy due to adhesions, if needed. For LVRS, the areas of pulmonary parenchyma exhibiting greatest destruction were resected with standard staplers (COVIDIEN Endo GIA ${ }^{\mathrm{TM}}$ Ultra Universal or ETHICON Echelon ENDOPATH ${ }^{\mathrm{TM}}$ ). 


\section{Follow up and outcome measures}

All pulmonary lung function tests were performed using a standard body plethysmograph and CO diffusion capacity (Zahn, Germany). The follow up after three months was performed at our institution as a routine follow up after LVRS. The further follow up (survival) was performed with telephone contact to the family doctor and/or the patient itself. Tumors were staged according to the TNM system [ $7^{\text {th }}$ edition, $\left.2010(23)\right]$.

\section{Statistical analysis}

Descriptive variables are expressed as median with range, counts with proportions or median and interquartile ranges (IQR), unless otherwise specified. Comparisons were done using the Wilcoxon matched-pair signed rank test. A P value of $<0.05$ was determined as significant. Kaplan-Meier estimation was used to depict survival.

All data and graphs were produced using SPSS (IBM Corp., Released 2013. IBM SPSS Statistics for Windows, Version 22.0. Armonk, NY, USA).

\section{Ethical approval}

This study was approved by the Swiss local ethics committee (2016-0076).

\section{Results}

Fourteen patients (eight females, six males) were operated on. Median age at time of operation was 63 (range, 52-77) years.

Three procedures were bilateral (21\%) and eleven unilateral. Eight have been performed by VATS (57\%) and six with conversion to an open procedure due to adhesions. In ten patients, the tumor was resected atypically (71\%) and in four patients with an anatomical segmental resection. All patients had lung volume reduction in addition (Table 2). Seven patients had heterogeneous emphysema $(50 \%)$ and seven showed intermediate heterogeneous morphology. Only in three patients the cancer diagnosis was proven before operation.

UICC (Unité Internationale Contre Cancer) stage IA was confirmed in eleven patients (79\%), stage IB in one patient and stage IV in one patient due to pleural metastasis. The sarcoma of the lung was not UICC staged (Table 2). Systematic lymph node dissection was performed only in two patients due to the severely impaired lung function in all patients. Therefore twelve patients had no pathological lymph node staging (86\%). No patient had adjuvant chemotherapy or radiotherapy according to decisions at the institution's tumor board.

Median hospitalization time was 9 (IQR, 7.75-12.5) days. Median postoperative drainage time was 6 (IQR, 4.75-8.25) days. Postoperative pneumothorax occurred in three patients $(21 \%)$ after chest tube removal and required a new drain. Three patients (21\%) had prolonged air leak longer than seven days and one of them needed re-operation for fistula closure. No other complications were reported. Perioperative 90-day mortality was zero, the patient with sarcoma died four months postoperatively.

Median pre-operative FEV1 predicted was $32.5 \%$ and improved significantly by $14 \%$ to a median FEV1 of $37 \%$ three months postoperative $(\mathrm{P}=0.002)$. Decrease of hyperinflation (RV/TLC) was significant by $9 \%$. The lung function values are listed in Table 3.

Follow up ranged from 6 to 126 months. Mean survival was 60 months (95\% CI: 37.715-82.285 months, Figure 1). Three-year survival rate was $50 \%$ and five-year survival was $36 \%$. From the eight deceased patients, one died because of the tumor, five because of pulmonary non-cancer related reasons and in two patients the reason of death is unknown.

\section{Discussion}

This retrospective study describes concomitant LVRS with lung cancer resection at our institution. The results imply an improved functional outcome after cancer resection with low morbidity and mortality and good long-term-survival.

LVRS leads to several improvements and benefits in selected patients with emphysema $(14,17,19,24)$, especially lung function improves and quality of life increases. Whereas anatomic lung resection offers the best longterm-survival in early stage NSCLC most patients with severe emphysema are precluded from surgery due to impaired lung function $(1,4,5,25)$. The latter is quoted in several international guidelines. However, several groups have reported their experience of combined lung cancer resection and LVRS which was done with the intention to symptoms of severe emphysema and to offer resection of early-stage lung cancer especially also to get tissue for final diagnosis which was not confirmed prior to surgery. Already in 1996, McKenna et al. operated on eleven emphysema patients with lung cancer (seven wedge resections and four lobectomies both combined with bilateral LVRS) and reported a more than 100\% increase 
Table 2 Patient's age, type of operation and cancer histology/stage

\begin{tabular}{|c|c|c|c|c|}
\hline Age & Operation & Histology & pTNM & UICC stage \\
\hline 70 & VATS unilateral LVRS right upper lobe & Sarcoma of the lung & pT1 cN0-1 CMO & - \\
\hline 63 & Open lingula resection and LVRS right upper lobe & Adenocarcinoma & pT1 cN0 cM0 & IA \\
\hline 69 & Open segment 6 resection and LVRS right upper lobe & Squamous cell carcinoma & pT1 pN0 cM0 & $\mathrm{IA}$ \\
\hline 69 & VATS bilateral LVRS upper lobes & Large cell carcinoma & pT1a cNO cMO & IA \\
\hline 77 & VATS unilateral LVRS left upper lobe & Squamous cell carcinoma & pT1a cNO cM0 & $\mathrm{IA}$ \\
\hline 72 & Open segment 6 resection and LVRS left lower lobe & Squamous cell carcinoma & pT1a pNo cM0 & IA \\
\hline 56 & Open LVRS right upper lobe & Adenocarcinoma & pT2a pN0 pM1a (pleura) & IV \\
\hline 58 & VATS unilateral LVRS right upper lobe & Large cell carcinoma & pT1a cNO MO & IA \\
\hline 52 & VATS bilateral LVRS upper lobes & Adenocarcinoma & pT1a cNO cMO & IA \\
\hline
\end{tabular}

LVRS, lung volume reduction surgery; VATS, video-assisted thoracic surgery.

Table 3 Lung function pre-operative and post-operative at 3 months

\begin{tabular}{lccc}
\hline Variable & Median preoperative, $\mathrm{n}=14[\mathrm{IQR}]$ & Median postoperative at 3 months, $\mathrm{n}=14$ [IQR] & P value compared to preoperative \\
\hline FEV1\% & $32.5[27-37]$ & $37.5[32-48]$ & 0.002 \\
FEV1, mL & $690[597-850]$ & $925[780-1,093]$ \\
TLC \% & $117[110-136]$ & $108[102-114]$ \\
TLC, mL & $6,260[5,480-8,500]$ & $5,710[5,060-7,200]$ & 0.014 \\
RV, \% & $187[171-241]$ & $147[123-196]$ \\
RV, mL & $4,010[3,240-5,335]$ & $3,020[2,525-4,158]$ & 0.002 \\
RV/TLC, \% & $64[62-70]$ & $58[54-62]$ & $32[26-44]$ \\
DLCO, \% & $30[23-39]$ & 0.001 & 0.116 \\
\hline
\end{tabular}

DLCO, diffusion capacity; FEV1, forced expiratory volume in 1 second; IQR, interquartile range; mL, milliliters; RV, residual volume; RV/ TLC, RV-TLC-ratio (= hyperinflation); TLC, total lung capacity.

in FEV1\% from pre- to postoperatively (26). Other studies mainly focused about lobectomies for cancer within an emphysematous lobe $(27,28)$. Carretta et al. operated on 10 patients and found significant functional improvement as well. Edwards et al. found no lung function changes three months postoperatively for patients with lobectomy of a poorly perfused and hyperinflated emphysematous lobe and pre-operative FEV1 less than $40 \%$ compared to a group with FEV1 greater than $40 \%$. They concluded that standard calculations of pre-operative FEV1 may be misleading in emphysema patients and selection criteria might be extended in these selected patients. Choong et al. conducted a review on 21 patients with severe emphysema where nine underwent lobectomy alone and twelve had a 


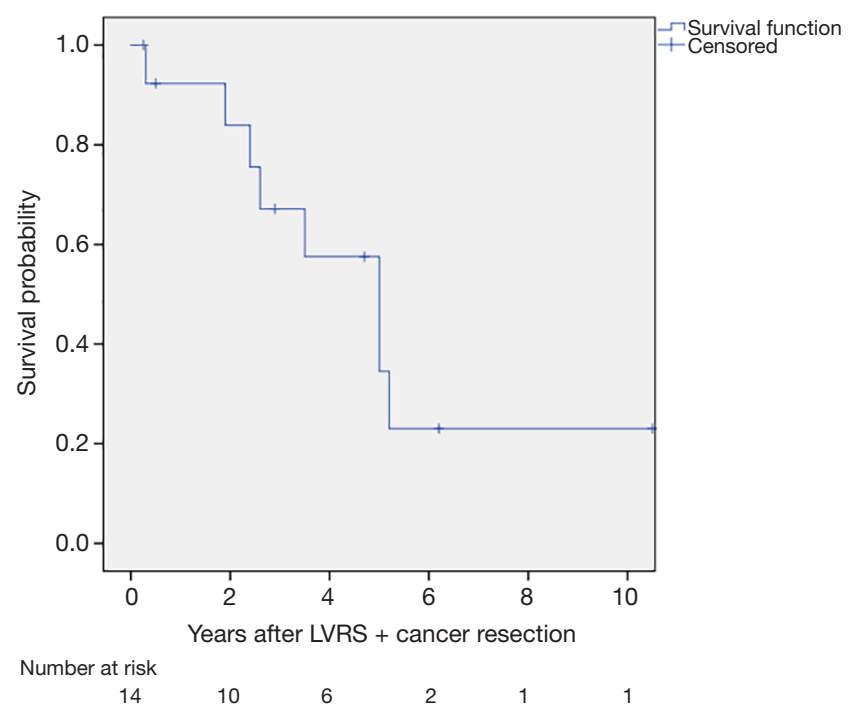

Figure 1 Kaplan-Meier graph of survival.

lobectomy [9] or a wedge resection [3] supplemented with LVRS (29). FEV1\% predicted increased by $38 \%$ within six months postoperatively.

Recently, Makey and colleagues compared maximal oxygen consumption (VO2 max) values from the American College of Chest Physicians (ACCP) guidelines and from the National Emphysema Treatment Trial (NETT) homogeneous non-upper lobe predominant emphysema (NULPD) surrogate for predicting operative mortalities (30). The "high-risk" cohort (VO2 max $<10 \mathrm{~mL} / \mathrm{kg} / \mathrm{min}$ ) showed lower predicted operative risk for NSCLC resection than the ACCP guidelines. ACCP guidelines patients (27) had an operative mortality of $26 \%$ and NETT's homogeneous NULPD patients (29) showed a mortality rate of $14 \%$. Eight-year survival rates in both compared groups were similar suggesting that LVRS did not shorten life span at this time point in patients with severe emphysema.

With pre-operative median values of FEV1 of predicted $32.5 \%$ and diffusion capacity of predicted $30 \%$ most of our patients might have been precluded from surgery and have undergone radiation therapy. Besides some theoretical research there is so far no evidence of lung volume reduction after radiation therapy (31). Our patient's perioperative morbidity is very low and the only relevant complication after surgery is prolonged air leak. Three patients (21\%) showed air leakage longer than seven days and one of them was re-operated for fistula closure. Prolonged air leak is a well-known issue after LVRS and ranges from $30 \%$ in our own cohort up to $57 \%$ in literature (32).
Linden and colleagues reported a $1 \%$ operative mortality rate from sublobar resection of lung tumors in 96 consecutive patients with preoperative FEV1 less than $35 \%$ of predicted (33). The 90-day mortality in our patients was zero and might be a reflection of our long-lasting experience in treating emphysema patients. Patients had to fulfill our selection criteria for LVRS (Table 1).

Five-year survival rate was $36 \%$ which is lower than in previous reported series $(62.7 \%)$ but most operations by Choong et al. were performed as anatomical resections (29). Lobectomy is still the standard of resection for lung cancer.

As limitation, this is a small retrospective review of highly selected patients and lung function follow-up values are only available for the first three months after operation. All potentially eligible patients for LVRS should be discussed at a multidisciplinary emphysema board at highly experienced centers (34). Therefore, indication is still the key issue and even in prospective trials only carefully selected patients will experience concomitant cancer resection and LVRS.

Primary radiation therapy might be proposed for patients with emphysema, impaired lung function and NSCLC but this strategy lacks the beneficial effect of lung volume reduction. Radiation therapy shows only few complications [i.e., pneumonitis (35)] but our patients after concomitant cancer resection and LVRS profit from low morbidity as well. LVRS is safe and effective in all types of emphysema morphology and therefore cancer resection heterogeneous and even in intermediately heterogeneous emphysema should be taken into account $(18,20,36)$. Again, one should observe standard selection criteria for LVRS.

From an oncological point of view sublobar resections are at least comparable with radiation therapy and therefore overall survival might be similar $(8,9)$. Three-year survival of $55.8 \%$ and 2 -year survival of $73 \%$ after radiation therapy is comparable with the 3 -year survival of $50 \%$ and the 5 -year survival of $36 \%$ in our patients. This comparison must be considered with caution as our study counts only on highly selected patients.

In conclusion, sublobar resection of early stage lung cancer combined with LVRS in patients with severe emphysema improves lung function and shows low morbidity and mortality. Oncological outcome is comparable to radiation therapy which lacks the beneficial effect of LVRS. Patient selection plays a key role and therefore lung cancer patients with emphysema should be discussed at a tumor board including thoracic surgeons with experience in LVRS or be presented at a multidisciplinary emphysema board. 


\section{Acknowledgements}

None.

\section{Footnote}

Conflicts of Interest: Meeting presentation-This study was presented as poster at the ESTS Annual Meeting in Naples, Italy, 29.05.2016-01.06.2016.

Ethical Statement: The study was approved by the Swiss Local Ethics Committee (No. 2016-0076).

\section{References}

1. Ginsberg RJ, Rubinstein LV. Randomized trial of lobectomy versus limited resection for T1 N0 non-small cell lung cancer. Lung Cancer Study Group. Ann Thorac Surg 1995;60:615-22; discussion 622-3.

2. Goldstraw P, Crowley J, Chansky K, et al. The IASLC Lung Cancer Staging Project: proposals for the revision of the TNM stage groupings in the forthcoming (seventh) edition of the TNM Classification of malignant tumours. J Thorac Oncol 2007;2:706-14.

3. Yano M, Yoshida J, Koike T, et al. Survival of 1737 lobectomy-tolerable patients who underwent limited resection for cStage IA non-small-cell lung cancer. Eur J Cardiothorac Surg 2015;47:135-42.

4. Bolliger CT, Wyser C, Roser H, et al. Lung scanning and exercise testing for the prediction of postoperative performance in lung resection candidates at increased risk for complications. Chest 1995;108:341-8.

5. Brunelli A, Charloux A, Bolliger CT, et al. ERS/ESTS clinical guidelines on fitness for radical therapy in lung cancer patients (surgery and chemo-radiotherapy). Eur Respir J 2009;34:17-41.

6. Brunelli A, Kim AW, Berger KI, et al. Physiologic evaluation of the patient with lung cancer being considered for resectional surgery: Diagnosis and management of lung cancer, 3rd ed: American College of Chest Physicians evidence-based clinical practice guidelines. Chest 2013;143:e166S-90S.

7. Colice GL, Shafazand S, Griffin JP, et al. Physiologic evaluation of the patient with lung cancer being considered for resectional surgery: ACCP evidencedbased clinical practice guidelines (2nd edition). Chest 2007;132:161S-77S.

8. Timmerman R, Paulus R, Galvin J, et al. Stereotactic body radiation therapy for inoperable early stage lung cancer. JAMA 2010;303:1070-6.

9. Lencioni R, Crocetti L, Cioni R, et al. Response to radiofrequency ablation of pulmonary tumours: a prospective, intention-to-treat, multicentre clinical trial (the RAPTURE study). Lancet Oncol 2008;9:621-8.

10. Carrafiello G, Mangini M, Fontana F, et al. Complications of microwave and radiofrequency lung ablation: personal experience and review of the literature. Radiol Med 2012;117:201-13.

11. Asai K, Nakamura K, Shioyama Y, et al. Clinical characteristics and outcome of pneumothorax after stereotactic body radiotherapy for lung tumors. Int J Clin Oncol 2015;20:1117-21.

12. Zemlyak A, Moore WH, Bilfinger TV. Comparison of survival after sublobar resections and ablative therapies for stage I non-small cell lung cancer. J Am Coll Surg 2010;211:68-72.

13. Safi S, Rauch G, op den Winkel J, et al. Sublobar Resection, Radiofrequency Ablation or Radiotherapy in Stage I Non-Small Cell Lung Cancer. Respiration 2015;89:550-7.

14. Criner GJ, Cordova F, Sternberg AL, et al. The National Emphysema Treatment Trial (NETT) Part II: Lessons learned about lung volume reduction surgery. Am J Respir Crit Care Med 2011;184:881-93.

15. Criner GJ, Cordova F, Sternberg AL, et al. The National Emphysema Treatment Trial (NETT): Part I: Lessons learned about emphysema. Am J Respir Crit Care Med 2011;184:763-70.

16. Ciccone AM, Meyers BF, Guthrie TJ, et al. Longterm outcome of bilateral lung volume reduction in 250 consecutive patients with emphysema. J Thorac Cardiovasc Surg 2003;125:513-25.

17. Hamacher J, Buchi S, Georgescu CL, et al. Improved quality of life after lung volume reduction surgery. Eur Respir J 2002;19:54-60.

18. Weder W, Tutic M, Lardinois D, et al. Persistent benefit from lung volume reduction surgery in patients with homogeneous emphysema. Ann Thorac Surg 2009;87:22936; discussion 236-7.

19. Bloch KE, Georgescu CL, Russi EW, et al. Gain and subsequent loss of lung function after lung volume reduction surgery in cases of severe emphysema with different morphologic patterns. J Thorac Cardiovasc Surg 2002;123:845-54.

20. Weder W, Tutic M, Bloch KE. Lung volume reduction surgery in nonheterogeneous emphysema. Thorac Surg 
Clin 2009; 19:193-9.

21. Russi EW, Stammberger U, Weder W. Lung volume reduction surgery for emphysema. Eur Respir J 1997;10:208-18.

22. Weder $W$, Thurnheer R, Stammberger U, et al. Radiologic emphysema morphology is associated with outcome after surgical lung volume reduction. Ann Thorac Surg 1997;64:313-9; discussion 319-20.

23. Tsim S, O'Dowd CA, Milroy R, et al. Staging of nonsmall cell lung cancer (NSCLC): a review. Respir Med 2010;104:1767-74.

24. Fishman A, Martinez F, Naunheim K, et al. A randomized trial comparing lung-volume-reduction surgery with medical therapy for severe emphysema. N Engl J Med 2003;348:2059-73.

25. Brunelli A, Charloux A, Bolliger CT, et al. The European Respiratory Society and European Society of Thoracic Surgeons clinical guidelines for evaluating fitness for radical treatment (surgery and chemoradiotherapy) in patients with lung cancer. Eur J Cardiothorac Surg 2009;36:181-4.

26. McKenna RJ Jr, Fischel RJ, Brenner M, et al. Combined operations for lung volume reduction surgery and lung cancer. Chest 1996;110:885-8.

27. Carretta A, Zannini P, Puglisi A, et al. Improvement of pulmonary function after lobectomy for non-small cell lung cancer in emphysematous patients. Eur J Cardiothorac Surg 1999;15:602-7.

28. Edwards JG, Duthie DJ, Waller DA. Lobar volume reduction surgery: a method of increasing the lung cancer resection rate in patients with emphysema. Thorax 2001;56:791-5.

Cite this article as: Caviezel C, von Rotz J, Schneiter D, Inci I, Hillinger S, Opitz I, Weder W. Improved postoperative lung function after sublobar resection of non-small-cell lung cancer combined with lung volume reduction surgery in patients with advanced emphysema. J Thorac Dis 2018;10(Suppl 23):S2704S2710. doi: 10.21037/jtd.2018.06.79
29. Choong CK, Meyers BF, Battafarano RJ, et al. Lung cancer resection combined with lung volume reduction in patients with severe emphysema. J Thorac Cardiovasc Surg 2004;127:1323-31.

30. Makey I, Berger RL, Cabral HJ, et al. Maximal Oxygen Uptake--Risk Predictor of NSCLC Resection in Patients With Comorbid Emphysema: Lessons From NETT. Semin Thorac Cardiovasc Surg 2015;27:225-31.

31. Binkley MS, Shrager JB, Leung AN, et al. Lung volume reduction after stereotactic ablative radiation therapy of lung tumors: potential application to emphysema. Int J Radiat Oncol Biol Phys 2014;90:216-23.

32. Ginsburg ME, Thomashow BM, Bulman WA, et al. The safety, efficacy, and durability of lung-volume reduction surgery: A 10-year experience. J Thorac Cardiovasc Surg 2016;151:717-24.e1.

33. Linden PA, Bueno R, Colson YL, et al. Lung resection in patients with preoperative FEV $1<35 \%$ predicted. Chest 2005;127:1984-90.

34. Rathinam S, Oey I, Steiner M, et al. The role of the emphysema multidisciplinary team in a successful lung volume reduction surgery programme†. Eur J Cardiothorac Surg 2014;46:1021-6; discussion 1026.

35. Ishijima $M$, Nakayama $H$, Itonaga $T$, et al. Patients with severe emphysema have a low risk of radiation pneumonitis following stereotactic body radiotherapy. Br J Radiol 2015;88:20140596.

36. Hamacher J, Bloch KE, Stammberger U, et al. Two years' outcome of lung volume reduction surgery in different morphologic emphysema types. Ann Thorac Surg 1999;68:1792-8. 